\title{
A Segurança Rodoviária Não é um Acidente: Desafios Para a Saúde
}

\section{Road Safety is No Accident: Challenges Facing the Healthcare Sector}

\author{
Bernardo GOMES $\triangle^{1,2}$, André PERALTA-SANTOS ${ }^{3,4}$, Maria MOITINHO DE ALMEIDA ${ }^{5}$ \\ Acta Med Port 2020 Apr;33(4):219-220 - https://doi.org/10.20344/amp.13540
}

Palavras-chave: Acidentes de Trânsito; Condução de Veículo; Portugal; Segurança

Keywords: Accidents, Traffic; Automobile Driving; Portugal; Safety

No ano de 2018, ocorreram em Portugal 34235 acidentes com vítimas e morreram 675 pessoas. ${ }^{1}$ Mais de 10 pessoas por semana, o equivalente a 66 mortes por cada milhão de habitantes - a União Europeia registou uma média de 49 óbitos por milhão no mesmo período.

A mortalidade rodoviária em Portugal foi das que mais decresceu desde 2010 (menos 35\% de óbitos) mas os esforços realizados não foram suficientes para alcançar a média europeia. Um dos resultados mais perturbadores do relatório da Autoridade Nacional de Segurança Rodoviária foi o aumento de $12 \%$ no número de mortos entre 2017 e 2018. A tendência de estagnação ou inversão na redução do número de mortes é visível em toda a União Europeia - é conhecida a relação da sinistralidade com ciclos económicos, mas existem mais determinantes a estudar.

Apesar da carga brutal que os acidentes rodoviários representam para a sociedade portuguesa - ao causarem mortes prematuras e incapacidades vitalícias - existem poucos estudos conhecidos que tracem o perfil destes acidentes nas nossas estradas recorrendo a técnicas modernas de geolocalização e a segmentação do perfil dos envolvidos.

O Plano Estratégico Nacional de Segurança Rodoviária - PENSE $2020^{2}$ mostrou resultados positivos no período de 2011 a 2015. Apesar da diminuição acelerada do número de mortes, o número de acidentes manteve-se, salientando a importância de fatores relacionados com o comportamento humano e gestão do sistema rodoviário (que inclui legislação, policiamento e informação).

Sugerimos quatro eixos que poderão beneficiar de maior envolvimento dos profissionais de saúde.

\section{Uma melhor utilização dos dados}

Os dados públicos disponíveis não permitem uma análise rigorosa de fatores de risco. Seria útil empreender métodos analíticos mais sofisticados para perceber de que forma as políticas de prevenção rodoviária influenciaram a evolução da sinistralidade. É necessário ir para além da mera identificação de pontos negros nas nossas estradas e da análise descritiva de relatórios. A comunidade científica poderia elaborar mapas de risco - mas para tal é necessário que estejam dados disponíveis para iniciativas colaborativas. Estes dados, anonimizados, deveriam ser um bem público.

A escassez de evidência transcende a realidade da sinistralidade e de Portugal: é um problema a nível global, embora existam exemplos de boas práticas. A cidade de Leeds e o Estado da Califórnia já partilham abertamente os seus dados de sinistralidade rodoviária (data.gov.uk; healthdata.gov); e em certos países nórdicos existem institutos especificamente dedicados à investigação em transportes e rodovias.

Propomos a divulgação alargada do 'perfil de risco' das estradas, em função da sinistralidade no último ano e nos últimos cinco anos. A sinalização à entrada de troços específicos com mensagens alusivas poderia ser reforçada e a construção de vias futuras teria evidência adicional disponível. A colaboração com recursos humanos qualificados é uma condição para que os dados, que já são recolhidos pelos diversos serviços do Estado, se transformem em mais conhecimento e melhores políticas.

\section{Estudar e mudar comportamentos}

Estudos internacionais sugerem que a estratégia mais eficaz para reduzir o número de acidentes da estrada é o policiamento para assegurar a aplicação da lei. As intervenções educacionais por si só provaram ser insuficientes na promoção de mudanças culturais, embora não devam ser descuradas como estratégia de suporte. ${ }^{3}$

Tal como referenciado pelo PENSE, ${ }^{2}$ parece haver persistência de comportamentos de risco, apesar de haver mais segurança. Condutores, passageiros e peões compreendem os riscos dos seus comportamentos e conhecem também o código da estrada. A investigação do tipo

\footnotetext{
1. Unidade de Saúde Pública Entre Douro e Vouga I. Departamento de Saúde Pública Administração Regional da Saúde Norte. Porto. Portugal.

2. Instituto de Saúde Pública. Universidade do Porto. Porto. Portugal.

3. Centro de Investigação em Saúde Pública. Universidade Nova de Lisboa. Lisboa. Portugal.

4. Department of Global Health. University of Washington. Washington. Estados Unidos da América.

5. Centre for Research on the Epidemiology of Disasters. Institute of Health and Society. University of Louvain. Ottignies-Louvain-la-Neuve. Bélgica.

$\triangle$ Autor correspondente: Bernardo Gomes. bernardomgomes@gmail.com

Recebido: 03 de fevereiro de 2020 - Aceite: 03 de fevereiro de 2020 | Copyright @ Ordem dos Médicos 2020
} 
qualitativo pode contribuir para revelar os mecanismos psicossociais que levam a estas atitudes de risco conscientes, o que poderia guiar futuras medidas de alteração de comportamentos. Existem iniciativas interessantes em que são aplicados métodos de ciências do comportamento e o seu papel no desenho e implementação de políticas, sendo a Behavioural Insights Team do Reino Unido o exemplo mais famoso.

As campanhas de sensibilização para a adopção de comportamentos seguros deve fazer parte de um pacote de políticas abrangentes, e devem fazer uso das novas plataformas. A temática da sinistralidade rodoviária deve continuar a ser abordada nos currículos escolares, sobretudo da óptica da prevenção com particular foco na sua magnitude anormal entre nós. O uso de telemóveis na estrada poderá ter um papel relevante nas estatísticas recentes, com particular foco nos acidentes dentro de localidades e atropelamentos. ${ }^{4} \mathrm{~A}$ recente campanha em Portugal "o meIhor presente é estar presente", dirigida à época das festas, deveria ter um eco longitudinal ajustado, mantendo-se ativa nos media e redes sociais por períodos de tempo mais longos. Finalmente, um dos maiores desafios é o consumo de álcool e de substâncias psicoativas. Estima-se que, globalmente, o álcool seja responsável por cerca de 30\% dos acidentes rodoviários, ${ }^{5}$ embora exista pouca informação sobre a realidade em Portugal.

É de extrema importância alterar a aceitabilidade social da combinação de álcool e condução, a começar pela facilidade de acesso em estações de serviço. Políticas direcionadas à diminuição do consumo terão, expectavelmente, impacto mais vasto na morbimortalidade, mas necessitam de ser desenhadas de acordo com as realidades existentes. O investimento em transportes públicos é também uma resposta útil a esta temática e de consequências alargadas.

\section{Reforma da regulação da habilitação dos condutores}

Atestados médicos para condução não devem ser apenas mais uma burocracia. Os centros de avaliação médica e psicológica tardam em sair do papel, o que leva a que esta função recaia sobretudo nos médicos de família. É ineficiente, e a possibilidade de emissão de atestado por qualquer médico não oferece um contexto regulatório adequado. O veículo automóvel tem um papel fundamental no quotidiano e na quebra de isolamento de uma parte substancial da população que não tem acesso a transportes públicos. Porém, a emissão de atestado e a supervisão das condições para condução carecem de critérios mais apertados para não colocar em risco a vida do próprio e terceiros.

\section{Formação e resposta a acidentes}

Dada a frequência dos acidentes rodoviários em Portugal, muitos profissionais de saúde serão confrontados com uma situação em que deverão prestar assistência em condições difíceis mesmo sem ter experiência em cuidados pré-hospitalares. Será importante durante os cursos superiores haver formação não só para reflectir sobre a temática como para estarem preparados a responder nestas situações. ${ }^{6}$ É imperativo também assegurar e reforçar a capacidade de resposta a acidentes multivítimas em todo o território nacional, sem prejudicar os cuidados de saúde habituais e com atenção a assimetrias geográficas. $\mathrm{O}$ apoio psicossocial às vítimas e suas famílias faz parte de um conjunto de necessidades, agudas e crónicas, geradas pelos acidentes rodoviários que não devem ser subestimadas.

Embora seja referida a participação da Saúde no PEN$\mathrm{SE}$, é claro que os profissionais de saúde devem pressionar soluções concretas e céleres para o flagelo da sinistralidade rodoviária. São os primeiros a saber que a cifra de 675 óbitos esconde um universo de incapacidade e sofrimento difícil de quantificar. O término do período do actual PENSE em 2020, e respetiva avaliação em 2021, será uma oportunidade para aumentar e melhorar a participação da Saúde. A criação de organismos de investigação, independentes e multidisciplinares, específicos desta temática é uma solução para garantir um futuro melhor. Mas os órgãos decisores devem estar recetivos a colaboração, para o melhor uso possível da evidência. É para o bem da nossa população: afinal de contas, a sinistralidade rodoviária não é um acidente.

\section{REFERÊNCIAS}

1. Autoridade Nacional de Segurança Rodoviária. Relatório Anual de Sinistralidade a 30 dias, 2018. [consultado 2020 jan 15]. Disponível em: http://www.ansr.pt/Estatisticas/RelatoriosDeSinistralidade/ Documents/2018/RELAT\%C3\%93RIO\%20ANUAL \%20-\%20 V\%C3\%8DTIMAS\%20A\%2030\%20DIAS/Relat\%C3\%B3rio\%20 Anual\%20Sinistralidade\%20Rodovi\%C3\%A1 ria\%202018\%2030d.pdf.

2. Resolução do Conselho de Ministros n. ${ }^{\circ} 85 / 2017$. Plano Estratégico Nacional de Segurança Rodoviária. Diário da República, i série, № 6 (2017/06/19). p.3054-89.

3. Aguilera SL, Moysés ST, Moysés SJ. Road safety measures and their effects on traffic injuries: a systematic review. Rev Panam Salud Publica.
2014;36:257-65.

4. World Health Organization. Mobile phone use: a growing problem of driver distraction. 2011. [consultado 2020 jan 15]. Disponível em: https:// www.who.int/violence_injury_prevention/publications/road_traffic/ distracted_driving_en.pdf.

5. Stephens AN, Bishop CA, Liu S, Fitzharris M. Alcohol consumption patterns and attitudes toward drink-drive behaviours and road safety enforcement strategies. Accid Anal Prev, 2017;98:241-51.

6. Coats TJ, Davies G. Prehospital care for road traffic casualties. BMJ. 2002;324:1135-8. 